\title{
Monensina sódica sobre vacas em fase inicial de lactação: produção de leite e peso vivo
}

\author{
Sodium monensin on early lactation cows: milk production and live weight
}

\author{
Carolina D'ávila Possatti ${ }^{\mathrm{II}}$ Ismail Ramalho Haddade ${ }^{\mathrm{I}}$ João Luis Kill $^{\mathrm{II}}$ Douglas Haese ${ }^{\mathrm{II}}$ \\ Alberto Chambela Neto ${ }^{I}$ Carla da Penha Simon ${ }^{I}$ Isabel Araújo Rocha ${ }^{\mathrm{I}}$ \\ João Vitor Miranda do Nascimento ${ }^{\mathrm{I}}$ Willian Alves Garcia ${ }^{\mathrm{I}}$
}

RESUMO

Avaliou-se o efeito do fornecimento de monensina sódica no desempenho de vacas leiteiras em fase inicial de lactação, cuja alimentação, em sua dieta total no cocho, compôsse em $81,4 \%$ de silagem de milho e 18,6\% de concentrado, em que se fez uso de maior proporção de silagem de milho de que concentrado. Foram utilizadas 14 vacas multíparas 7/8 Holandês, aos $20 \pm 10$ dias pós-parto aproximadamente, com média de $22 \pm 0,5 \mathrm{~kg} \mathrm{vaca}^{-1}$ dia $^{-1}$ de leite, em delineamento de blocos casualizados, adotando-se o esquema de parcelas subdivididas no tempo, em modelo de medidas repetidas. Os tratamentos nas parcelas foram diferenciados pela presença (200mg animal ${ }^{-1}$ dia $^{-1}$ ) ou ausência da monensina na ração e, nas subparcelas, pelos diferentes períodos de avaliação. Não se observaram diferenças no consumo em matéria seca da dieta, conversão alimentar, produção de leite in natura e corrigida e peso vivo nas médias diárias de cada período. No entanto, a produção de sólidos totais foi superior para os tratamentos com o ionóforo, sinalizando que a administração da monensina sódica para vacas no início de lactação modifica o rendimento em produção de leite.

Palavras-chave: consumo, ganho de peso, início de lactação, ionóforo, produção de leite.

\section{ABSTRACT}

The effect on the performance of early lactation cows when supplying them with sodium monensin was evaluated, whose power in their overall diet in the trough, was composed of $81.4 \%$ of corn silage and $18.6 \%$ of concentrate in which use was made of a higher proportion of corn silage to concentrate. Fourteen multiparous 7/8 Dutch cows were used, approximately $20 \pm 10$ days post-labor, with the average weight of $22 \pm 0.5 \mathrm{~kg} \mathrm{cow}^{-1}$ day $^{-1}$ of lactation, in randomized blocks, adopting the scheme of subdivided portions in time and repetitive measurement model. The treatments in portions were differentiated by the presence $(200 \mathrm{mg}$. animal $\left.^{-1} d a y^{-1}\right)$ or absence of monensin in the food and, in the subportions, different evaluation periods were used. The animals were fed with their total diet in the feeder composed of $81.4 \%$ of corn silage and $18.6 \%$ of concentrate. No difference was found in the consumption of diet dry matter, alimentary conversion, in natural and corrected production of milk and live weight in the daily averages of each period. However, the production of total solids was superior for treatments with ionophore, signalizing that the administration of sodium monensin in early lactation cows changes the milk production performance.

Key words: consumption, weight gain, early lactation, ionophore, milk production.

\section{INTRODUÇÃO}

Diante da proibição oriunda da União Europeia desde 2006, erradicou-se o uso de antibióticos nas rações como promotores de desempenho. Assim, em busca do maior desempenho animal, estudos relacionados aos ionóforos tornaramse frequentes e, esses aditivos vêm sendo utilizados, atualmente, na dieta de ruminantes para o aumento da eficiência energética (RODRIGUES et al.,2001)

Segundo OLIVEIRA et al. (2005), ionóforos diminuem o consumo de matéria seca devido ao aumento do tempo de permanência do alimento no trato digestivo, ocasionando melhoria na eficiência alimentar. Conforme GANDRA et al. (2010), a redução de consumo é mais evidenciada em vacas no terço médio e final de lactação. VAN DER MERWE et al. (2001), complementam que a

\footnotetext{
Instituto Federal de Educação, Ciência e Tecnologia do Espírito Santo (IFES), Santa Teresa, ES, Brasil.

"Programa de Mestrado em Ciência Animal, Universidade Vila Velha (UVV), 29102-606, Vila Velha, ES, Brasil. E-mail:carol_possatti@hotmail.com. Autor para correspondência.
}

IIUVV, Vila Velha, ES, Brasil. 
monensina é capaz de aumentar a taxa de ganho de peso e reestabelecer o escore de condição corporal pós-parto.

Muitos são os estudos que mostram os efeitos dos ionóforos diretamente relacionados à dieta, em que maior proporção de carboidrato é capaz de reduzir o consumo sem influenciar no ganho de peso, gerando, assim, uma melhora na condição alimentar (VARGAS et al., 2001). De acordo com VARGAS et al. (2001), a monensina foi capaz de diminuir o consumo de matéria seca a partir do aumento gradativo de concentrado (25\%. $50 \%$ e $75 \%$ de concentrado). É relatado por RODRIGUES et al. (2001) que a digestibilidade da fibra e da proteína é aumentada à medida que se diminui a proporção de volumoso na dieta. Assim, trabalhos que buscam evidenciar o efeito da monensina para dietas com elevada proporção de volumosos apresentam caráter inovador.

Dentre os principais objetivos do uso de ionóforos para bovinos leiteiros, destacam-se, sobre a produção de leite, os benefícios ligados à ação na fermentação ruminal e ao ajuste para a melhoria do rendimento do leite em extrato seco. No entanto, a ação da monensina, aliada aos fatores de estágio de lactação, de quantidade e tipo de volumoso, de quantidade de concentrado na dieta e do potencial do animal, deve ser estudada para maiores esclarecimentos sobre os efeitos desse aditivo na eficiência produtiva de leite.

Dessa forma, objetivou-se avaliar o efeito da adição de monensina sódica, em 200mg vaca ${ }^{-1}$ dia $^{-1}$, sobre a produção de leite, o consumo de matéria seca e a conversão alimentar de vacas, em fase inicial de lactação.

\section{MATERIAL E MÉTODOS}

Experimento conduzido de janeiro a maio de 2013 no setor de Bovinocultura Leiteira do Instituto Federal de Educação, Ciência e Tecnologia do Espírito Santo: Campus Santa Teresa (IFES-ST). Utilizaram-se 14 vacas multíparas, 7/8 Holandês, com aproximadamente $20 \pm 10$ dias pós-parto e produção média de $22 \pm 0,5 \mathrm{~kg}$ vaca $^{-1} \mathrm{dia}^{-1}$. Implantouse o experimento em delineamento experimental de blocos ao acaso, com sete repetições. Constituiu-se cada unidade de um animal, avaliado em cada um dos diferentes períodos pós-início do experimento, em esquema de parcelas subdivididas no tempo (Split plot) (STEEL et al., 1997). Dividiram-se os 120 dias em quatro períodos de 30 dias (0 a 30; 30 a 60, 60 a 90 e 90 a 120 dias). Alocaram-se, nas parcelas, dois tratamentos, considerando o fator monensina sódica, caracterizados pela ausência e ou pela presença do ionóforo (200mg vaca ${ }^{-1}$ dia $^{-1}$ ) na ração e, nas subparcelas, diferentes períodos pós-início da aplicação, considerados no mesmo animal.

Dietas isoenergéticas e isoproteicas formuladas para atender ou exceder às recomendações do NRC (2001) para vacas em produção, com média de $22 \mathrm{~kg} \mathrm{dia}^{-1}$ de leite e $3,5 \%$ de gordura, conforme produções determinadas pelos animais incluídos no ensaio. Proporção dos ingredientes e composição bromatológica das rações foram determinadas anteriormente ao experimento por meio de amostragens dos volumosos e concentrados. A dieta fornecida compôs-se de $81,4 \%$ de silagem de milho e $18,6 \%$ de concentrado $(7,5 \%$ de milho triturado, $9,4 \%$ de farelo de soja e $1,7 \%$ de mistura mineral, quantidade indicada pelo fabricante contendo 150/200g de Ca e 60g de Fósforo). A composição química foi composta por $34,7 \%$ de $\mathrm{MS}, 41,7 \%$ de FDN, $25,7 \%$ de FDA, $11,5 \%$ de PB, 2,6\% de EE, $63 \%$ de NDT, $39 \%$ de CNF, 1,52 $\mathrm{Mcal} \mathrm{kg}^{-1}$ de Energia Líquida. $\mathrm{O}$ balanço de nutrientes da dieta em relação ao requerimento efetivou-se em Energia Metabolizável (Mcal) 119\%, Proteína Metabolizável (g) $110 \%$, Nitrogênio não proteico (NNP) $100 \%$. Mistura mineral comercial para vacas em lactação. Composição por kg de mistura mineral: Ca-150/200g; P-60g; Mg-17,5g; Na-70g; S-11g; I-64mg; F-567mg; Mn-769mg; Cu-769mg; Fe-1.025mg; Co-44mg; Se-18mg; Zn-2.500mg; Vit A-200.00 UI; Vit D350.000UI; Vit E-1.250UI.

No período experimental, as vacas foram mantidas em regime de confinamento (120dias), alocadas em praça de alimentação a céu aberto, dotada de sombra, com cocho de volumoso e bebedouro automático. Receberam alimentação duas vezes ao dia ( 8 h e 15 h 30 min), disponibilizando-se silagem de milho à vontade. Realizaram-se duas ordenhas diárias seguidas do fornecimento de concentrado em cochos individuais, localizados próximos à sala de ordenha.

A monensina foi ministrada junto a uma mistura mineral (premix mineral) própria para ingestão forçada, adicionada ao concentrado em quantidade a possibilitar o consumo do ionóforo, em $200 \mathrm{mg}$ animal ${ }^{-1} \mathrm{dia}^{-1}$, considerando-se os períodos de adaptação estabelecidos, desde o primeiro dia de experimento, (1 a 7 dias, 50mg animal ${ }^{-1} \mathrm{dia}^{-1}$; de 8 a 16 dias, $100 \mathrm{mg}$ animal ${ }^{-1} \mathrm{dia}^{-1}$, e de 17 a 120 dias, 200mg animal $^{-1} \mathrm{dia}^{-1}$ ).

Para avaliação do consumo de concentrado, quantificou-se a ingestão por meio da diferença entre o fornecido e a sobra. Para o consumo 
de volumoso, utilizaram-se estimativas por meio do uso do marcador externo "hidroxifenilpropano modificado e enriquecido (LIPER)" (SALIBA et al., 2003). O marcador externo foi administrado por meio de cápsula comercial com $0,5 \mathrm{~g}$, diariamente, por via oral, em quatro períodos de sete dias, conforme descrito: Período I: do $23^{\circ}$ ao $30^{\circ}$ dia; Período II: do 53ํa a $60^{\circ}$ dia; Período III: do $83^{\circ}$ ao $90^{\circ}$ dia; Período IV: do $113^{\circ}$ ao $120^{\circ}$ dia. Os dois primeiros dias de cada período foram de adaptação ao fornecimento do indicador e, após esses, realizou-se a coleta de fezes duas vezes ao dia até o sétimo dia, conforme descrição de SALIBA et al. (2003).

Realizou-se, individualmente, a coleta de leite nas duas ordenhas, durante três dias (segunda, quarta e sexta) a cada semana. Calcularam-se as médias, para cada um dos períodos experimentais considerados. Para a produção de leite, foram consideradas as quantidades in natura e, posteriormente, corrigidas para 3,5\% de gordura, utilizando-se da equação citada por LEIVA et al. (2000), em que:

$\mathrm{PL}_{\text {corr }}=\left(12,82 * \mathrm{P}_{\text {gordura }}\right)+\left(7,13 * \mathrm{P}_{\text {proteína }}\right)+\left(0,323 * \mathrm{P}_{\text {leite }}\right)$

$\mathrm{PL}_{\text {corr }}$ : Produção de leite corrigida para $3,5 \%$ de gordura;

$\mathrm{P}_{\text {gordura }}$ : Produção de gordura;

$\mathrm{P}_{\text {proteína }}^{\text {gordura }}$ Produção de proteína;

$\mathrm{P}_{\text {leite }}$ : Produção de leite in natura;

Para dosagem dos sólidos totais, uma vez a cada 30 dias, coletaram-se amostras individuais de leite por animal (alíquotas de $2 \%$ do total de leite produzido por animal) em duas ordenhas consecutivas. Avaliou-se a composição química do leite através da técnica de infravermelho, em um aparelho Bentley 2000, no Laboratório Clínica do Leite $^{a}$, em Piracicaba - SP.

Os animais foram pesados e classificados quanto ao escore corporal, seguindo determinações do NRC (2001), a cada 15 dias logo após a ordenha matinal.

Para obtenção dos dados de conversão alimentar (kg de matéria seca da dieta total kg de leite corrigido $^{-1}$ ), avaliou-se a razão do total em matéria seca da dieta consumida pelo animal (volumoso + concentrado)e produção de leite corrigida, considerada individualmente por unidade experimental (vaca em cada período pré-estabelecido).

Realizou-se análise estatística por meio do modelo univariado de parcelas subdivididas no tempo, utilizando-se o SAEG 9.1 (2007). Para análise dos fatores (intra-sujeitos), realizou-se o teste de esferecidade de Mauchly, para verificar se a matriz de covariâncias dos erros atenderia à condição de simetria composta (similaridade de variâncias e correções nulas). Ao se verificar esferecidade insatisfatória $(\mathrm{P}<0,05)$, realizaram-se correções dos graus de liberdade dos fatores de subparcela por meio de GreenHouse-Geisser. Recalcularam-se os erros de tipo I e efetivou se a correção por meio do modelo linear geral do programa SPSS Statistics 20, seguindo o protocolo de medidas repetidas no tempo. Anteriormente à análise de variância testou-se cada variável quanto à homogeneidade de variâncias (teste de Bartlet) e à normalidade dos resíduos (teste de Lilliefors), fazendo uso do programa SAEG 9.1 (2007). Avaliaram- se, então, os efeitos dos tratamentos e dos blocos em cada idade de avaliação.

Para casos de interação significativa (monensina x período), fixaram-se os efeitos de cada período para posterior comparação das médias, entre os diferentes tratamentos (com e sem monensina). Para tanto, utilizou-se o teste de Scott-Knott a 5\% de probabilidade, por meio do programa SAEG 9.1, considerando-se as correções dos graus de liberdade bem como dos quadrados médios dos resíduos, gerados na análise de variância para medidas repetidas.

\section{RESULTADOS E DISCUSSÃO}

Verificou-se que as composições nutricionais das dietas oferecidas atenderam, em sua totalidade, aos requerimentos das vacas utilizadas no estudo (grupo de animais em início de lactação com produção média de $22 \mathrm{~kg} \mathrm{dia}^{-1}$ de leite e teores de gordura de $3,5 \%$ ).

Os níveis de carboidratos não fibrosos (39\% da MS) mostraram-se adequados, dentro dos limites estabelecidos de 30 a $45 \%$. Isso reduz a possibilidade de disfunções metabólicas por excesso (acidose) ou por falta (deficiência de substrato para rápida fermentação). Por estarem os níveis de FDN dentro do limite máximo de $41 \%$ de matéria seca, há o reforço para não ocorrência de disfunções por excesso ou falta de carboidratos na dieta. Fato esse comprovado pela ausência de disfunções metabólicas nos animais do experimento.

Porém, a utilização da monensina sódica não resultou em diferenças $(\mathrm{P}>0,05)$ relacionadas às seguintes variáveis: consumo de matéria seca total (em kg vaca ${ }^{-1}$ dia $^{-1}$ e em \% do peso vivo) e conversão alimentar com base no leite fluido corrigido e produção de sólidos totais. Não havendo, também, diferenças para os fatores principais, nem para interação (Tabela 1).

Provavelmente, a não diferença no consumo de matéria seca entre os animais suplementados com 
Tabela 1- Médias observadas, coeficiente de variação e valores dos erros experimentais para os efeitos principais (com e sem a monensina MON e período - PER) e sua interação (MON x PER) sobre o consumo de matéria seca da dieta, conversão alimentar e as produções de leite in natura e corrigida para 3,5\% de gordura em vacas Holandesas no início da lactação.

\begin{tabular}{|c|c|c|c|c|c|c|c|c|c|}
\hline \multirow{2}{*}{ Item } & \multicolumn{4}{|c|}{---------Médias nas diferentes idades--------- } & \multirow[t]{2}{*}{ Média geral } & \multirow{2}{*}{$\begin{array}{c}\text { Média geral }^{\mathrm{a}} \\
\mathrm{CV}(\%)^{\mathrm{b}}\end{array}$} & \multicolumn{3}{|c|}{-----------------Valor de P-------------. } \\
\hline & $0-30$ & $30-60$ & $60-90$ & $90-120$ & & & MON & PER & MON X PER \\
\hline \multicolumn{10}{|c|}{ 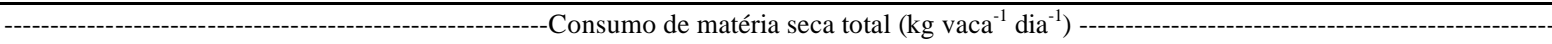 } \\
\hline Sem monensina & 16,27 & 16,20 & 16,13 & 16,07 & $16,17^{\mathrm{d}}$ & $16,16^{\mathrm{a}}$ & 0,9236 & $0,137^{\mathrm{c}}$ & $0,8740^{\mathrm{c}}$ \\
\hline Com monensina & 16,30 & 16,15 & 16,14 & 16,06 & $16,16^{\mathrm{e}}$ & $1,45 \% \%^{\mathrm{b}}$ & - & - & - \\
\hline \multicolumn{10}{|l|}{--------------------- } \\
\hline Sem monensina & 3,00 & 3,00 & 3,03 & 2,96 & $2,10^{d}$ & $2,99^{\mathrm{a}}$ & 0,9459 & $0,079^{\mathrm{c}}$ & $0,143^{\mathrm{c}}$ \\
\hline Com monensina & 3,03 & 3,00 & 3,03 & 2,94 & $3,00^{\mathrm{e}}$ & $2,68 \%^{\mathrm{b}}$ & - & - & - \\
\hline & & & & ---Con & são Alimenta & ------- & & & \\
\hline Sem monensina & 1,15 & 1,04 & 1,08 & 1,04 & $1,08^{\mathrm{d}}$ & $1,04^{\mathrm{a}}$ & 0,3870 & $0,689^{\mathrm{c}}$ & $0,191^{\mathrm{c}}$ \\
\hline Com monensina & 0,98 & 1,08 & 1,03 & 0,99 & $1,02^{\mathrm{e}}$ & $11,24 \%^{\mathrm{b}}$ & - & - & - \\
\hline \multicolumn{10}{|c|}{ - } \\
\hline Sem monensina & 19,22 & 19,35 & 17,61 & 15,95 & $18,03^{\mathrm{d}}$ & $18,51^{\mathrm{a}}$ & 0,1919 & $0,000002^{f}$ & $0,305^{\mathrm{f}}$ \\
\hline Com monensina & 21,73 & 19,80 & 17,69 & 16,71 & $18,98^{\mathrm{e}}$ & $9,78 \%{ }^{\mathrm{b}}$ & - & - & - \\
\hline & & 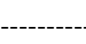 & $---P_{1}$ & Ição de le & corrigida $(\mathrm{k}$ & $\left.\operatorname{dia}^{-1}\right)-$ & & & \\
\hline Sem monensina & 14,52 & 16,21 & 15,73 & 15,93 & $15,60^{\mathrm{d}}$ & $15,99^{\mathrm{a}}$ & 0,3895 & $0,906^{\mathrm{f}}$ & $0,106^{\mathrm{f}}$ \\
\hline \multirow[t]{2}{*}{ Com monensina } & 17,36 & 15,85 & 16,00 & 16,36 & $16,39^{\mathrm{e}}$ & $10,28 \%^{\mathrm{b}}$ & & & \\
\hline & & & Produç & Sólidos To & no leite $(\mathrm{k}$ & $\left.\mathrm{dia}^{-1}\right)-----$ & & & \\
\hline Sem monensina & 1,95 & 2,20 & 1,81 & 1,81 & $1,94 \mathrm{~B}^{\mathrm{d}}$ & $2,05^{\mathrm{b}^{*}}$ & 0,0126 & $0,00100^{\mathrm{f}}$ & $0,22^{\mathrm{f}}$ \\
\hline Com monensina & 2,39 & 2,41 & 1,87 & 1,96 & $2,16 \mathrm{~A}^{\mathrm{e}}$ & $11,42 \%{ }^{b^{*}}$ & - & - & - \\
\hline
\end{tabular}

c-Valores do erro alfa para os efeitos de Período (PER) e de sua interação com os da Monensina (MON x PER), avaliados intra-sujeitos (medidas repetidas), corrigidos pelo coeficiente de GreenHouse-Geiser, para o recálculo dos erros nas subparcelas.

f-Valores de P para os efeitos de Período (PER) e de sua interação com os da Monensina (MON x PER), avaliados intra-sujeitos (medidas repetidas), corrigidos pelo coeficiente de GreenHouse-Geisser, para o recálculo dos erros nas subparcelas.

d-Média geral dos tratamentos sem monensina.

e- Média geral dos tratamentos com monensina.

* As médias seguidas por letras maiúsculas distintas, diferem-se entre si pelo teste Scott-Knott a 5\% de probabilidade.

monensina sódica e animais do grupo controle dá-se pela fase de lactação e pela quantidade de concentrado presente na dieta. A fase de lactação influencia, pois vacas em início de lactação e em fase de transição, não sofrem efeito de depressão do consumo, pois a concentração de insulina, nesse período encontrase baixa, o que justifica o fato do presente estudo não ter diminuição no consumo de matéria seca nos animais suplementados com monensina sódica. Assim, a monensina sódica não se torna suficiente para agir sobre o consumo de matéria seca nessa fase. De acordo com BORGES et al. (2008), uma das consequências do uso da monensina é a redução do consumo de matéria seca quando os animais se alimentam apenas para suprir exigências energéticas. Todavia, quando em balanço energético negativo, a energia adicional promovida pelo ionóforo é utilizada para melhorar o desempenho produtivo e/ou reduzir as perdas de reservas corporais. EIFERT et al. (2005), ao compararem os efeitos da monensina e óleo de soja, também obtiveram dados que confirmam o presente estudo: a não influência da monensina sódica sobre o consumo de matéria seca em vacas em início de lactação.

Em relação aos níveis de concentrado na dieta, a monensina sódica não causou diminuição no consumo de matéria seca, supostamente, pela baixa proporção de concentrado em relação ao volumoso (20:80), o que explica o consumo estável dos animais que receberam ionóforo, quando comparados ao grupo controle. Relata-se que a monensina expressa maiores efeitos, se fornecida em dietas com altos níveis de carboidratos, por propiciar mais substrato para produção de glicose. VARGAS et al. (2001) confirmam a suposição supracitada quando relatam que a monensina sódica é capaz de reduzir o consumo de matéria seca de acordo com o nível de concentrado oferecido na dieta.

Faz-se também necessário ressaltar que a literatura não esclarece dosagem a ser utilizada para diferentes concentrados ou diferentes volumosos. Portanto, a resposta observada com o uso da silagem de milho, como volumoso, ainda não está totalmente definida. 
A ausência do efeito do ionóforo na conversão alimentar $(\mathrm{P}>0,05)$ é resultado da ausência de diferenças na produção de leite corrigido (Tabela 1), bem como no consumo de matéria seca (Tabela 1). Esse fato é reforçado com a redução do erro experimental para efeito de tratamento (de $\mathrm{P}=0,3870$ para $\mathrm{P}=0,0543$ ) quando consideradas as conversões por $\mathrm{kg}$ de leite fluido e por kg de estrato seco.

Ao se relacionar a produção de leite tanto in natura quanto à corrigida para 3,5\% de gordura, não há diferenças $(\mathrm{P}>0,05)$ (Tabela 1$)$. No entanto, destaca-se o fato do erro tipo I para a interação dos efeitos da monensina e período (MON x PER) para o caso da produção de leite corrigida, situar-se em torno de $10,6 \%$. Ressalta-se que, pelo efeito do ionóforo, provável diferença poderia ocorrer, manifestada sobretudo na fase inicial de sua aplicação (período de 0 a 30 dias). Contudo, o fato da não manifestação de diferenças significativas entre efeitos da monensina nessa fase $(\mathrm{P}>0,05)$ não permite que as afirmações passem de meras especulações a respeito do fato.

A produção de leite, no experimento realizado, não sofreu influência da monensina sódica, supostamente, pelo não aumento das concentrações de lactose (Tabela 1) e pela fase de lactação. ANDRIGHETTO et al. (2005) confirmam a suposição ao afirmarem que a monensina não aumenta a produção de leite para vacas no início de lactação, uma vez que, nessa fase, ocorrem mudanças no peso corporal que interferem tanto na produção de leite quanto na reprodução. Quando avaliada a composição do leite, apenas o efeito principal do ionóforo (MON - tabela 1) apresentou diferença $(\mathrm{P}<0,05)$ na quantidade de sólidos totais no leite (Tabela 1). Esse resultado, além de fundamentar a comprovação do efeito positivo da monensina sobre o rendimento produtivo das vacas, uma vez que indica a produção de leite em matéria seca, ainda reforça as especulações anteriores em que as diferenças, quanto à produção de leite corrigida, demonstram que, uma vez adicionados os efeitos da produção de leite corrigida (Tabela 1) ao aumento das concentrações de sólidos totais, verifica-se superioridade na produção de matéria seca do leite, em $\mathrm{kg} \mathrm{vaca}^{-1} \mathrm{dia}^{-1}$.

A análise dos resultados de peso e a condição de escore corporal (ECC) não observou diferenças significativas $(\mathrm{P}>0,05)$ entre o grupo suplementado com a monensina sódica e grupo controle (Tabela 2). Indicando que as modificações de peso corporal durante a fase incial de lactação estariam muito mais condicionadas aos efeitos da fase de transição e balanço energético negativo do que propriamente aos efeitos benéficos da monensina.

Os resultados obtidos por VAN DER MERWE et al. (2001) vêm ao encontro dos alcançados no presente trabalho, em que não houve diferença significativa para o peso vivo dos vacas, comparandose os tratamentos. Assemelham-se, também, aos de GANDRA et al. (2010) e ANDRIGHETTO et al. (2005) este, em búfalas Murrah e, aqueles, em vacas em que a monensina não apresentou efeito em relação ao escore de condição corporal.

\section{CONCLUSÃO}

A monensina sódica melhora o desempenho de vacas em produção de sólidos totais de leite vaca dia, em fase inicial de lactação.O grau de desempenho e a manifestação de diferenças pelo uso da monensina podem não se manifestar devido às pequenas diferenças pelo uso desses produtos e aos

Tabela 2 - Estimadores para os efeitos principais (com e sem monensina - MON e Período - PER) e sua interação (MON x PER) sobre os pesos vivos, em kg vaca ${ }^{-1}$, e para os escores de condição corporal (de 1 a 5) em diferentes idades pós-início do experimental em vacas Holandesas no início da lactação.

\begin{tabular}{|c|c|c|c|c|c|c|c|c|c|c|c|c|c|}
\hline \multirow[t]{2}{*}{ Item } & \multicolumn{8}{|c|}{---------Dias pós-início do experimento---------- } & \multirow[t]{2}{*}{ Média Geral } & \multirow{2}{*}{$\begin{array}{c}\text { Média }^{\mathrm{a}} \\
\mathrm{CV}(\%)^{\mathrm{b}}\end{array}$} & \multicolumn{3}{|c|}{-----------Valor de P------------. } \\
\hline & 14 & 28 & 45 & 59 & 75 & 90 & 106 & 120 & & & MON & PER & MON X PER \\
\hline \multicolumn{14}{|c|}{$\left(\mathrm{kg} \mathrm{vaca}^{-1}\right)$} \\
\hline Sem monensina & 549 & 540 & 550 & 533 & 528 & 542 & 541 & 548 & $541,37^{\mathrm{d}}$ & $543^{\mathrm{a}}$ & 0,8682 & $0,0100^{\mathrm{c}}$ & $0,8030^{\mathrm{c}}$ \\
\hline Com monensina & 550 & 540 & 553 & 536 & 535 & 543 & 546 & 557 & $545,00^{\mathrm{e}}$ & $2,31 \%^{\mathrm{b}}$ & - & - & - \\
\hline Sem monensina & - & - & 3,21 & 3,07 & 2,86 & 3,07 & 3,00 & 3,14 & $3,06^{d}$ & $3,00^{\mathrm{a}}$ & - & - & $N S^{d}$ \\
\hline Com monensina & - & - & 3,00 & 3,07 & 2,93 & 2,86 & 2,71 & 2,93 & $2,92^{\mathrm{e}}$ & $10,05 \%^{\mathrm{b}}$ & & & \\
\hline
\end{tabular}

${ }^{a}$ Valores de P para os efeitos de Período (PER) e de sua interação com os da Monensina (MON x PER), avaliados intra-sujeitos (medidas repetidas), corrigidos pelo coeficiente de Green House-Geiser, para o recálculo dos erros nas subparcelas.

d-Média geral dos tratamentos sem monensina.

e- Média geral dos tratamentos com monensina. 
elevados níveis de volumoso na dieta utilizada neste estudo (acima de 80\%).

\section{FONTE DE AQUISIÇÃO}

CLÍNICA DO LEITE - ESALQ/USP- Departamento de Zootecnia, Escola Superior de Agricultura "Luiz de Queiroz" (ESALQ) Universidade de São Paulo (USP).

\section{AGRADECIMENTOS}

Agradecemos ao Centro de Tecnologia Animal (CTA), Instituto Federal de Educação, Ciência e Tecnologia do Espírito Santo (IFES), a Nutriave Alimentos e a Coordenação de Aperfeiçoamento de Pessoal de Nível Superior (CAPES) por possibilitarem a realização dessa pesquisa.

\section{REFERÊNCIAS}

ANDRIGHETTO, C. et al. Efeito da Monensina Sódica sobre a Produção e composição do Leite, a Produção de Mozzarela e o Escore de Condição Corporal de Búfalas Murrah. Revista Brasileira de Zootecnia, v.34, n.2, p.641-649, 2005. Disponível em: <http://www. scielo.br/scielo.php?pid=S1516-35982005000200034\&script $=$ sci arttext>. Acesso em: 06 maio, 2013. doi: 10.1590/S151635982005000200034 .

BORGES, L. F. O. et al. Efeitos da enramicina e da monensina sódica no consumo de matéria seca, na fermentação ruminal e no comportamento alimentar em bovinos alimentados com dietas com alto nível de concentrado. Revista Brasileira de Zootecnia, v.37, n.4, p.681-688, 2008. Disponível em: <http://www.scielo.br/scielo. php?script $=$ sci_arttext $\&$ pid $=S 1516-35982008000400014>$. Acesso em: 15 ago. 2013. doi: 10.1590/S1516-35982008000400014.

EIFERT, E. D. C. et al. Efeito da combinação de óleo de soja e monensina na dieta sobre o consumo de matéria seca e a digestão em vacas lactantes. Revista Brasileira de Zootecnia, v. 34 , n.6, p. 297-308, 2005. ISSN 1516-3598. Disponível em: <http://www.scielo.br-/scielo.php?script=sci_arttext\&pid=S151635982005000100034\&nrm=iso>. Acesso em: 15 ago. 2013. doi: 10.1590/S1516-35982005000100034.

GANDRA, J. R. Productive performance and milk protein fraction composition of dairy cows supplemented with sodium monensin. Revista Brasileira de Zootecnia, v.39, n.8, p.1810-1817, 2010. Disponível em: <http://www.scielo.br/scielo.php?pid=S1516- 35982010000800025\&script=sci_arttext $>$. Acesso em: 07 maio, 2013. doi: 10.1590/S1516-35982010000800025.

NATIONAL RESEARCH COUNCIL. Nutrient requirements of dairy cattle. 7.ed. Washington, DC: National Academic, 2001. 260p.

OLIVEIRA, M. V. M. et al. Influência da monensina no consumo e na fermentação ruminal em bovinos recebendo dietas com teores baixo e alto de proteína. Revista Brasileira de Zootecnia, v.34, n.5, p.1763-1774, 2005. Disponível em: <http://www.scielo.br/scielo. php?pid=S1516-35982005000500038\&script=sci_arttext $>$. Acesso em: 23 mar. 2013. doi: 10.1590/S1516-35982005000500038 .

RODRIGUES, P. H. M. et al. Monensina e digestibilidade aparente em ovinos alimentados com proporções de volumoso/ concentrado1. Scientia Agricola, v.58, n.3, p.449-455, 2001. Disponível em: <http://www.scielo.br/scielo.php?script=sci_artte xt\&pid=S0103-90162001000300002 > . Acesso em: 25 mar. 2014. doi: 10.1590/S0103-90162001000300002.

SAEG, Sistema para Análises Estatísticas, Versão 9.1. Viçosa: Fundação Arthur Bernardes - UFV, 2007.

SALIBA, E. O. S. et al. Utilization of purified lignin extracted from Eucaliptusgrandis (PELI) used as an external marker in digestibility trial in various animal species. In: WORLD CONFERENCE AN ANIMAL PRODUCTION, 9, 2003, Porto Alegre, RS. Proceedings... 2003, p. 25-38.

SPSS, Statistics for Windows, Version 20.0. Armonk, New York: IBM Corp. 2011.

STEEL, R. G. et al. Split-Plot designs. In: Principles and procedures of statistics: a biometrical aproach. 3 . ed. USA. The MacGraw-Hill Company. 1997, p. 420-425.

VARGAS, L. H. et al. Influência de Rumensin ${ }^{\circledR}$, Óleo de Sojae Níveis de concentrado sobre o Consumo e os Parâmetros Fermentativos Ruminais em Bovinos. Revista Brasileira de Zootecnia, v.30, n.5, p.1650-1658, 2001. Disponível em: <http://www.scielo.br/ scielo.php?pid=S1516-35982001000600035\&script=sci_arttext $>$. Acesso em: 13 set. 2013. doi: 10.1590/S1516-35982001000600035.

VAN DER MERWE, B. J. et al. The effect of monensin on milk production, milk urea nitrogen and body condition score of grazing dairy cows. South African Journal of Animal Science, v.31, n.1, p.49-55, 2001. Disponível em: <http://www.sasas.co.za/ effect-monensin-milk-production-milk-urea-nitrogen-and-bodycondition-score-grazing-dairy-cows>. Acesso em: 21 out. 2013. 